\title{
Second-Hand Infant Care Plastic Products Sold in Markets of Kalar City, Kurdistan Region, Iraq: Heavy Metals Contamination and Risk Assessment
}

\author{
Hayder Mohammed Issa, Azad H. Alshatteri \\ College of Human Sciences, University of Garmian \\ Chemistry Department,College of Education, University of Garmian
}

\begin{abstract}
In this study, health risk assessment and contamination have been performed of fourteen toxic heavy metals in six second-hand plastic infant care products collected from markets of Kalar city, Kurdistan region of Iraq. Secondhand infant care plastic products might impose serious health concerns if they contain high levels of heavy metals. The toxic heavy metal elements concentrations have been identified and analyzed using inductively coupled plasma optical emission spectroscopy (ICPOES, Spectro Arcos). Many of the investigated products contain considerable or high levels of the examined heavy metals according to the European Union EU safety limits for brittle, pliable, liquid and sticky toy materials. The highest level of heavy metals has been noticed was of zinc $10643.4 \mathrm{mg} / \mathrm{kg}$ in sample ST1 (183\% higher than the allowable limit). High concentrations of lead Pb, mercury $\mathrm{Hg}$, and chrome $\mathrm{Cr}$ have also detected. Statistical analysis of Pearson correlation matrix $\mathrm{CM}$, and hierarchical cluster analysis HCA found significant correlations between many heavy metals and infant care samples respectively. Health risk assessment for sample ST6 identified a moderate significant hazard index regarding heavy metals of arsenic, mercury, and cobalt with $\mathrm{HI}$ values of $0.5652,0.2967$ and 0.1211 respectively. This work leads thus safety measure is respected in the investigated infant care samples. Furthermore, stringent procedures are needed to limit the handling and importing of such products into the markets in the future.
\end{abstract}

\section{Introduction}

Environmental contamination is increasingly becoming a matter of a great global issue (Oke 2004). Contamination of commercial products and foodstuff with toxic elements is now a vital factor concerning human health (Kakimov et al. 2013; Stef and Gergen 2012). Plastic toys are objects that very often used by children and infants for playing and enjoyment. Toys and other infant care products are necessary factors during the progression of the infant's life (Landrigan et al. 2004). Therefore the exposure to a number of toxic elements and heavy metals presented in in fants are possibly greater through the mouthing of toys and non-food products (Landrigan and Goldman 2011). Many infant and child-care products may contain various harmful components such as toxic elements and heavy metals in their compositions (Becker et al. 2010). Hence the main potential source of exposure and transfer of dangerous chemicals and toxic elements to infants is through their toys (Decharat 2017; Earls et al. 2003).

Despite the fact, the heavy metals are naturally existing in soil and rocks (Marcovecchio et al. 2007). Toxic elements like heavy metals are considered as the most detrimental contaminants regarding their nonbiodegradable behavior (Kopp et al. 2018). They tend to accumulate in biological systems like the human body (Kim et al. 2015). Heavy metals present in the environment may involve essential and to xic heavy metals (Issa and Alshatteri 2018; Mahmood et al. 2012). The essential metals are $\mathrm{Co}, \mathrm{Cr}, \mathrm{Fe}, \mathrm{Mn}, \mathrm{Mo}, \mathrm{Ni}$, $\mathrm{Se}, \mathrm{Sn}, \mathrm{V}, \mathrm{Cu}$, and $\mathrm{Zn}$, these metals are critical for sustaining biological life within a certain range (Nkono 
and Asubiojo 1997). Accumulation of critical heavy metals in the human body also is unsafe and may cause harmful consequences (Nahar and Zhang 2012). While the toxic and non-essential heavy metals of $\mathrm{Cd}, \mathrm{Pb}, \mathrm{Al}, \mathrm{As}, \mathrm{Ba}, \mathrm{Hg}, \mathrm{Be}$, and Ti are highly toxic and may caus e chronic poisoning (Duruibe et al. 2007).

Infants or children care products that contain toxic elements are posing a detrimental health risk to this specific age group (Felter et al. 2015). As infants and toddlers are frequently mouthing objects for long durations (Finch et al. 2015). For example, in fant's exposure to toxic elements such as Mn, As and Cd by way of ingestion of infant care product resulted in severe cases of poisoning associated with neurodevelopment and behavioral disorders (Ciesielski et al. 2012; Rodríguez-Barranco et al. 2013). While ingestion and exposure to $\mathrm{PVC}$ products contain $\mathrm{Pb}$ may result in serious acute or chronic adverse effects may lead to death (VanArsdale et al. 2004). Moreover, a low dose of these heavy metal has various effects on the infant's health, especially on the brain and nervous system (Lanphear et al. 2005). Exposure of infants to heavy metals in toys is not the only migratable way to their body, water and food are additional exposure risk certain toxic elements (Luca et al. 2018; Scheuplein et al. 2002). Studies on this issue showed that many in fant care products were contaminated with various toxic elements such as $\mathrm{Cd}, \mathrm{Cu}, \mathrm{Ni}$, As, Se, Hg, Cr, Zn, Co and Sb (Grynkiewicz-Bylina 2011; Korfali et al. 2013; Rebelo et al. 2015).

Recently, the raised awareness on the presence of toxic elements in infant care products provoked many regulations adopted to limit their consequences (Goldman 1998; Hervey and McHale 2004; Wigle et al. 2007). The United States consumer product safety commission (CPSC) recalled many toy or children jewelry products (Weidenhamer et al. 2011). The adopted toys and infant care safety regulations are applied for new products, whereas are not for the second-hand and older products. Although the secondhand children and infants products are an alternative choice for their cheap prices (Miller and Harris 2015). Second-hand infant care products are mostly old plastic products despite their good looking condition, likely due to the durability of synthetic polymers and paints (Turner 2018). In developed countries, Iraq, the tendency to buy re-used or second-hand stuff (Nada Abdulrahman and Faiza Kadhim 2017), child-care products are more extensively because of the economic situation.

Even though second-hand plastic infant care products are available abundantly in Iraqi markets and in homes, no study has been conducted in Iraq to investigate and assess the presence of toxic elements in second-hand children's toys and jewelry that sold in markets. Toxic elements and metalloids, including harmful heavy metals present in these products, can cause dangerous effects for infants and toddlers. Since the current regulations and mandatory limits dealing with second-hand infant care products are not employed effectively in Kurdistan, Iraq.

The present study describes the first investigation in this field. The current work aims to determine the occurrence of toxic elements present in second-hand plastic infant care products in Iraq. Six samples of these products were taken from Iraqi markets and used to determine the concentrations of the 19 toxic elements. Selected samples were analyzed using inductively coupled plas ma optical emission spectrosco py ICP-OES to assess the potential for exposure for toxic elements through ingestion.

\section{Methods and Materials}

\subsection{Sample Collection and Preparation}

Six second-hand plastic infant care samples were collected from different locations in Iraqi markets (ST1 ST6). The tested plastic samples are infant's teethers and pacifiers. These samples are inexpensive products, were chosen because they are widely bought by peoples and such products are most likely contain higher toxic elements concentrations (Kang and Zhu 2015). All toys samples were thoroughly cleaned to remove dust and any undesirable dirt. The samples have been milled. The grinded samples were then stored in containers and labeled and prepared for analysis. 


\subsection{Element Analysis in Infant Care Samples}

Inductively coupled plasma optical emission spectroscopy ICP-OES, Spectro Arcos was used to analysis 14 potentially toxic elements and heavy metals. The investigated elements are $\mathrm{Al}, \mathrm{As}, \mathrm{Ba}, \mathrm{Cd}, \mathrm{Co}, \mathrm{Cr}, \mathrm{Cu}$, $\mathrm{Hg}, \mathrm{Mn}, \mathrm{Ni}, \mathrm{Pb}, \mathrm{Se}, \mathrm{V}$, and $\mathrm{Zn}$. The instrument operation conditions used for analysis were: Sp ray chamber is Scott spray; Nebulizer: crossflow; RF power/W: 1400; pu mp speed: $30 \mathrm{RPM}$; Coolant flow (L/min): 14; Auxiliary flow (L/min): 0.9; nebulizer gas flow ( $/ \mathrm{min})$ : 0.8; Pre flush (s): 40; Measure time (s): 28; replicate measurement: 3 ; argon gas (purity $\geq 99.99$ ); multi-elements stock solutions containing $1000 \mathrm{mg} / \mathrm{L}$ were obtained from Bernd Kraft (Bernd Kraft GmbH, Du isburg, Germany); standard solutions were diluted by several dilution into $0.1,0.5,2 \mathrm{ppm}$ in $0.5 \%$ nitric acid as diluent.

\subsection{Health Risk Assessment of Infant Care Samples}

The risk assessment method of infant care samples was applied using the existing previously methods proposed by (Guney et al. 2014). Infants at this age from 6 to 12 months are frequently mouthing toys and objects (Smith and Norris 2003). For saline extraction that simulates the chemical daily intake CDI from the saliva is determined by the following:

$$
C D I_{\text {Saliva }}=\frac{(B a c * E D)}{B W}
$$

where $B_{a c}$ is the bioaccessible quantity of an element in saliva (saline extraction) for 30 min of exposure $(\mu \mathrm{g} / \mathrm{min}), \mathrm{ED}$ is the daily exposure time (30 min /day), and BW is the average weight of infant's boy which is assumed to be about $9.2 \mathrm{~kg}$ for 6-12 month old (U.S. EPA 2005). For this work, $10 \mathrm{~g}$ was selected as an average value, $\mathrm{ED}$ of $66 \mathrm{~min} / \mathrm{d}$ was used for $6-12$ months old children (Cui et al. 2015). Using specific exposure durations and the same average weight of infant's boy for same age category: the chemical daily intake from ingestion of the toy sample (acid extraction) CDI was also calculated as follows

$$
C D I_{\text {ingestion }}=\frac{R_{m g} * E F}{B W}
$$

where $R_{m g}$ is the rate of migration bioaccessible fraction of metals in the $0.07 \mathrm{M} \mathrm{HCl}$ acid extraction $(\mu \mathrm{g} / \mathrm{min})$, and $\mathrm{EF}$ is the exposure duration $(\mathrm{min} / \mathrm{d})$ assuming $1 \mathrm{~h} / \mathrm{d}$ of playtime has mouthing time of 26 $\mathrm{min} / \mathrm{h}$ for 6-12 months old infants (Guney et al. 2014). $10 \mathrm{~g}$ of the sample was considered as mentioned above. A hazard index HI for oral exposure and ingestion of elements was established as the following

$$
H I=\frac{C D I}{R f D}
$$

where RfD is the reference dose for a potentially toxic element, the RfD for toxic elements investigated in this work $(\mu \mathrm{g} / \mathrm{kg}$ d) are $\mathrm{Al}=750 ; \mathrm{Ba}=600 ; \mathrm{Cd}=0.5 ; \mathrm{Co}=1.4 ; \mathrm{Cr}=5 ; \mathrm{Cu}=83 ; \mathrm{Hg}=2 ; \mathrm{Mn}=160 ; \mathrm{Ni}=$ $10 ; \mathrm{Pb}=3.6 ; \mathrm{Se}=5 ; \mathrm{Zn}=500$ were adapted from (Van Engelen et al. 2009). While RfD in ( $\mu \mathrm{g} / \mathrm{kg}$ d) for As $=0.3 ; \mathrm{V}=3$ were adapted from (Agency for Toxic Substances and Disease Registry (ATSDR) 2017).

To assess the accuracy of the digestion method, one selected sample material analysis was duplicated.

\subsection{Statistical Analysis}

Three statistical analysis techniques were performed for the concentration of the toxic element in the second-hand infant care products. Analysis of variance ANOVA was first applied to examine differences in the average concentration of the elements in infant care products. The correlations and relations between 
metal concentrations in second-hand infant care products were explored using Pearson correlation matrix $\mathrm{CM}$ analysis. Agglomerative hierarchical clustering AHC was applied in this work to classify samples according to their content variation of toxic and heavy metal. Ward-algorithmic linkage method and Euclidean distance are the basis to conduct statistical cluster analysis. Cluster analysis was performed using XLSTAT (version 2017 for Excel 2013 software).

\section{Results and Discussion}

\subsection{Toxic Elements Concentrations in Second-Hand Plastic Infant Care Samples}

Concentrations of 14 toxic elements in the examined second-hand infant care products are shown in Table 1. The Eu ropean Union EU safety limits (Eu ropean Council 2009) for brittle, pliable, liquid and sticky toy material were being listed in Table 1 for comparison. The results illustrate that all samples are containing various levels of toxic elements. At first glance, it seems the sample ST1 has the highest toxic elements concentrations of $\mathrm{Cr}, \mathrm{Hg}$, and $\mathrm{Zn}$ that exceed the safety limits set by the European Union for migratable elements. In sample ST1, the excess percentage of concentrations of $\mathrm{Cr}, \mathrm{Hg}$, and $\mathrm{Zn}$ than the European Union limits are $82.69 \%, 87.75 \%$, and $183.23 \%$ respectively. High concentrations of Cr exist also in samples ST2, ST3 and ST5 with excess percentages of $77.4 \%, 55.67 \%$ and $89.66 \%$ than European Union limit of $37.5 \mathrm{mg} / \mathrm{kg}$ respectively. Pb had concentrations in samples ST3 and ST4 by $102.35 \%$ and $98.21 \%$ respectively higher than European safety limit of $13.5 \mathrm{mg} / \mathrm{kg}$. Other toxic elements have high concentrations but still within the European Union safety limits. There is not a clear migration limit for vanadium yet, so any presence of this toxic metal in the examined samples may be regarded as a source with a potentially harmful effect on infant health.

However, the analysis of the six second-hand infant care samples by ICP-OES proved that mostly all the 14 examined to xic elements and metals have been added in such products. Many of these elements are used in plastic products due to their stabilizing property. Where $\mathrm{Pb}$ has great stabilizing property if it was compared to other metals (Greenway and Gerstenberger 2010). Recently, increasing concern about the harmful effect of lead on health made many producers to use alternatives to this metal (Levin et al. 2008; Mizuno et al. 1999). A mong the alternatives to reduce the use of $\mathrm{Pb}$ in toys production, manufacturers are now increasingly utilizing $\mathrm{Cd}$ (Hillyer et al. 2014). For this reason, a high concentration of $\mathrm{Pb}$ is always found in old plastic products (Jaksland et al. 2000). Besides $\mathrm{Pb}$, the $\mathrm{Cr}$ high concentrations in most of the samples are probably added due to the coloring property of $\mathrm{Cr}$ materials such as lead chromates to paint toys and infant care products (Erkens et al. 2001). The results showed that high concentrations of $\mathrm{Hg}$ and $\mathrm{Zn}$ were found in sample ST1 as follows: 14.081 and $10643.357 \mathrm{mg} / \mathrm{kg}$ for $\mathrm{Hg}$ and $\mathrm{Zn}$ respectively. These concentrations exceed the European Union safety limits for migratable toxic elements $\mathrm{Hg}$ and $\mathrm{Zn}$ in toys that are 7.5 and $3750 \mathrm{mg} / \mathrm{kg}$ respectively. For $\mathrm{Zn}$ high concentration is observed in sample ST1, this ele ment is used in infant care products as zinc borate for flame retardation (Shen et al. 2008). While $\mathrm{Hg}$ was generally added to PVC toys for its antifungal and antibacterial property (Delgado et al. 2011; Tulve et al. 2015). However, some the other toxic elements are existing in the examined infant care samples with relatively high concentrations but they still within the limits proposed by European Union safety limits.

Table 1. Toxic elements concentrations in infant care plastic samples $(\mathrm{mg} / \mathrm{kg})$.

\begin{tabular}{lcccccccc}
\hline $\begin{array}{l}\text { Toxic } \\
\text { elements }\end{array}$ & ST1 & ST2 & ST3 & ST4 & ST5 & ST6* & DML (GML) & LOD \\
\hline Description & & & & & & & -- & -- \\
Al & & & 147.21 & & & & $5625(1406)$ & 0.0040 \\
& 249.995 & 165.317 & 2 & 71.755 & 345.137 & 0.117 & & \\
As & 0.674 & 0.919 & 0.723 & 0.473 & 0.925 & 0.006 & $3.8(0.9)$ & 0.0026 \\
Ba & 0.924 & 0.224 & 2.195 & 0.797 & 1.000 & 0.009 & $4500(1125)$ & 0.0044 \\
Cd & ND & 0.050 & 0.100 & 0.050 & 0.075 & 0.001 & $1.9(0.5)$ & 0.0010
\end{tabular}




\begin{tabular}{lcccccccc}
$\mathrm{Co}$ & 0.225 & 0.174 & 0.200 & 0.149 & 0.200 & 0.006 & $10.5(2.6)$ & 0.0010 \\
$\mathrm{Cr}$ & 68.509 & 66.524 & 58.376 & 25.762 & 71.122 & 0.000 & $37.5(9.4)$ & 0.0010 \\
$\mathrm{Cu}$ & 17.302 & 4.248 & 3.767 & 5.182 & 8.946 & 0.127 & $622(156)$ & 0.0010 \\
$\mathrm{Hg}$ & 14.081 & 4.745 & 4.191 & 3.937 & 4.323 & 0.021 & $7.5(1.9)$ & 0.0040 \\
$\mathrm{Mn}$ & 24.568 & 3.975 & 5.563 & 3.862 & 8.597 & 0.003 & $1200(300)$ & 0.0010 \\
$\mathrm{Ni}$ & 2.147 & 0.894 & 1.622 & 0.698 & 1.075 & 0.004 & $75(18.8)$ & 0.0010 \\
$\mathrm{~Pb}$ & 1.223 & 2.807 & 27.317 & 26.759 & 10.571 & 0.001 & $13.5(3.4)$ & 0.0035 \\
$\mathrm{Se}$ & 0.849 & 0.547 & 0.524 & 0.374 & 0.675 & 0.010 & $37.5(9.4)$ & 0.0020 \\
$\mathrm{~V}$ & 0.100 & 0.099 & 0.100 & 0.050 & 0.050 & 0.000 & $--(--)$ & 0.0025 \\
$\mathrm{Zn}$ & 10643.35 & & 136.98 & & & & $3750(938)$ & 0.0010 \\
& 7 & 283.808 & 4 & 159.755 & 214.314 & 0.091 & & \\
\hline
\end{tabular}

DML: dry migration limit ( $\mathrm{mg} / \mathrm{kg}$ ) for brittle and pliable toy material (European Council 2009); GML: gustative migration limit ( $\mathrm{mg} / \mathrm{kg}$ ) for liquid and sticky toy material (European Council 2009) adaptable for sample ST6; LOD: limit of detection (mg/L) of ICP-OES used for analysis; BDL: Below detection limit; * liquid continent in sample ST6.

\subsection{Statistical Analysis of Toxic Elements Concentrations in Samples}

An analysis of variance ANOVA was performed to explore the presence of significant differences among second-hand infant care samples examined in this study. ANOVA was employed for variation of average toxic element concentrations in the samples and without replications using a $95 \%$ confidence level. The results of variance analysis showed that there are no statistically significant differences between infant care samples (ST6 was excluded in the analysis as its condition is quite different) at a confidence level of $95 \%$ ( $\mathrm{p}$-value > 0.05). Where $\mathrm{p}$-value was 0.422 , the $\mathrm{F}$ value was 0.986 , and $\mathrm{F}_{\text {crit }}$ was 2.513 .

The relations between the toxic element concentrations in the examined samples was investigated using Pearson's correlation. The correlation matrix in Table 2 displays that there are many strong positive correlations between toxic elements. $\mathrm{Pb}, \mathrm{Ba}$, and $\mathrm{Cd}$ have no correlations with other elements. It can be observed that Se has more corre lations than other elements; Se has strong positive correlations with each of $\mathrm{Al}, \mathrm{As}, \mathrm{Co}, \mathrm{Cr}, \mathrm{Hg}, \mathrm{Cu}$, and $\mathrm{Ni}$. Correlation matrix also shows a strong positive relationship exists among $\mathrm{Ni}, \mathrm{Co}, \mathrm{Cr}$, Se and V. Similarly, another strong positive corre lation was observed among the elements Mn, $\mathrm{Cu}, \mathrm{Hg}$, and $\mathrm{Zn}$. Weak or negative correlations between the elements are also noticed in the samples. In general, for the examined infant care samples, positive strong correlations between specific elements means that any changing in the concentration of one of them will be followed by changes in the related elements. Otherwise, weak or no correlations between some ele ments existed in the samples such as $\mathrm{Cd}, \mathrm{Pb}$ and Ba propose that changes in the concentration of one of these elements have no effects the concentration of the others.

Table 2. Correlation matrix (Pearson) of toxic elements in second-hand infant care samples.

\begin{tabular}{ccccccccccccccc}
\hline Elements & $\mathrm{Al}$ & $\mathrm{As}$ & $\mathrm{Ba}$ & $\mathrm{Cd}$ & $\mathrm{Co}$ & $\mathrm{Cr}$ & $\mathrm{Cu}$ & $\mathrm{Hg}$ & $\mathrm{Mn}$ & $\mathrm{Ni}$ & $\mathrm{Pb}$ & $\mathrm{Se}$ & $\mathrm{V}$ & $\mathrm{Zn}$ \\
\hline $\mathrm{Al}$ & $\mathbf{1 . 0 0}$ & $\mathbf{0 . 8 1}$ & 0.32 & 0.30 & 0.79 & $\mathbf{0 . 8 8}$ & 0.70 & 0.55 & 0.61 & 0.64 & -0.11 & $\mathbf{0 . 8 7}$ & 0.47 & 0.36 \\
$\mathrm{As}$ & $\mathbf{0 . 8 1}$ & $\mathbf{1 . 0 0}$ & 0.40 & 0.58 & $\mathbf{0 . 8 8}$ & $\mathbf{0 . 9 5}$ & 0.44 & 0.41 & 0.34 & 0.60 & 0.14 & $\mathbf{0 . 8 3}$ & 0.76 & 0.10 \\
$\mathrm{Ba}$ & 0.32 & 0.40 & $\mathbf{1 . 0 0}$ & 0.71 & 0.61 & 0.44 & 0.19 & 0.22 & 0.23 & 0.65 & 0.72 & 0.43 & 0.52 & 0.04 \\
$\mathrm{Cd}$ & 0.30 & 0.58 & 0.71 & $\mathbf{1 . 0 0}$ & 0.46 & 0.42 & -0.25 & -0.28 & -0.32 & 0.18 & 0.73 & 0.21 & 0.35 & -0.56 \\
$\mathrm{Co}$ & 0.79 & $\mathbf{0 . 8 8}$ & 0.61 & 0.46 & $\mathbf{1 . 0 0}$ & $\mathbf{0 . 9 2}$ & 0.70 & 0.70 & 0.64 & $\mathbf{0 . 8 7}$ & 0.28 & $\mathbf{0 . 9 5}$ & $\mathbf{0 . 8 5}$ & 0.42 \\
$\mathrm{Cr}$ & $\mathbf{0 . 8 8}$ & $\mathbf{0 . 9 5}$ & 0.44 & 0.42 & $\mathbf{0 . 9 2}$ & $\mathbf{1 . 0 0}$ & 0.63 & 0.62 & 0.58 & 0.78 & -0.01 & $\mathbf{0 . 9 3}$ & $\mathbf{0 . 8 2}$ & 0.36 \\
$\mathrm{Cu}$ & 0.70 & 0.44 & 0.19 & -0.25 & 0.70 & 0.63 & $\mathbf{1 . 0 0}$ & $\mathbf{0 . 9 5}$ & $\mathbf{0 . 9 8}$ & 0.80 & -0.22 & $\mathbf{0 . 8 6}$ & 0.50 & $\mathbf{0 . 8 9}$
\end{tabular}




\begin{tabular}{ccccccccccccccc}
$\mathrm{Hg}$ & 0.55 & 0.41 & 0.22 & -0.28 & 0.70 & 0.62 & $\mathbf{0 . 9 5}$ & $\mathbf{1 . 0 0}$ & $\mathbf{0 . 9 7}$ & $\mathbf{0 . 8 7}$ & -0.21 & $\mathbf{0 . 8 4}$ & 0.66 & $\mathbf{0 . 9 4}$ \\
$\mathrm{Mn}$ & 0.61 & 0.34 & 0.23 & -0.32 & 0.64 & 0.58 & $\mathbf{0 . 9 8}$ & $\mathbf{0 . 9 7}$ & $\mathbf{1 . 0 0}$ & $\mathbf{0 . 8 4}$ & -0.27 & 0.81 & 0.53 & $\mathbf{0 . 9 5}$ \\
$\mathrm{Ni}$ & 0.64 & 0.60 & 0.65 & 0.18 & $\mathbf{0 . 8 7}$ & 0.78 & 0.80 & $\mathbf{0 . 8 7}$ & $\mathbf{0 . 8 4}$ & $\mathbf{1 . 0 0}$ & 0.12 & $\mathbf{0 . 8 9}$ & $\mathbf{0 . 8 3}$ & 0.72 \\
$\mathrm{~Pb}$ & -0.11 & 0.14 & 0.72 & 0.73 & 0.28 & -0.01 & -0.22 & -0.21 & -0.27 & 0.12 & $\mathbf{1 . 0 0}$ & 0.00 & 0.16 & -0.40 \\
$\mathrm{Se}$ & $\mathbf{0 . 8 7}$ & $\mathbf{0 . 8 3}$ & 0.43 & 0.21 & $\mathbf{0 . 9 5}$ & $\mathbf{0 . 9 3}$ & $\mathbf{0 . 8 6}$ & $\mathbf{0 . 8 4}$ & 0.81 & $\mathbf{0 . 8 9}$ & 0.00 & $\mathbf{1 . 0 0}$ & 0.78 & 0.62 \\
$\mathrm{~V}$ & 0.47 & 0.76 & 0.52 & 0.35 & $\mathbf{0 . 8 5}$ & $\mathbf{0 . 8 2}$ & 0.50 & 0.66 & 0.53 & $\mathbf{0 . 8 3}$ & 0.16 & 0.78 & $\mathbf{1 . 0 0}$ & 0.42 \\
$\mathrm{Zn}$ & 0.36 & 0.10 & 0.04 & -0.56 & 0.42 & 0.36 & $\mathbf{0 . 8 9}$ & $\mathbf{0 . 9 4}$ & $\mathbf{0 . 9 5}$ & 0.72 & -0.40 & 0.62 & 0.42 & $\mathbf{1 . 0 0}$ \\
\hline
\end{tabular}

Values in bold are different from 0 with a significance level alpha $=0.05$

Hierarchical cluster analysis HCA identifies the similarity among clustered results of infant care samples, by showing considerable internal clusters homogeneity. From the results presented in Figure 1, the HCA dendrogram has generated three distinct clusters (groups). The similarity of infant care samples in term of toxic elements concentrations are categorized into three principal clusters. Cluster 1, involves ST4 and ST2 samples. Cluster 2 is one sample of ST1. Cluster 3, contains samples of ST3 and ST5. The cluster classification analysis shows the samples are mainly divided on the basis of type and toxic elements concentrations. Sample ST1 was defined as an independent cluster (cluster 2), considering that the sample showed in some way different elements concentrations (high levels of $\mathrm{Zn} \mathrm{Hg}$ and $\mathrm{Cu}$ ). In cluster 3, Samples are most likely were grouped as per low concentrations of some heavy metals in their compositions.

\subsection{Risk Assessment of Heavy Metals in Infant Care Samples}

In the final part of this work, risk assessment of a second-hand sample, ST6, has been conducted using a hazard index (HI) for the determined heavy metals. The sample ST6 was chosen to achieve the risk analysis because its special condition of containing liquid inside, which is easy could be transferred to the infant's mouth and then to their bodies. The special case of sample ST6 has made no need to apply ingestion and mouthing tests, the concentrations in the sample liquid have been considered for hazard indexcalculation. Depending on the designated values of the chemical intake and doses of the investigated heavy metals in sample ST6, the calculated HI has been classified into three groups: HI is higher than 1, the risk is significant, $\mathrm{HI}$ is between $1-0.1$, the risk is moderately significant, and $\mathrm{HI}$ is less than 0.1 , the risk is neglected (Cui et al. 2015).

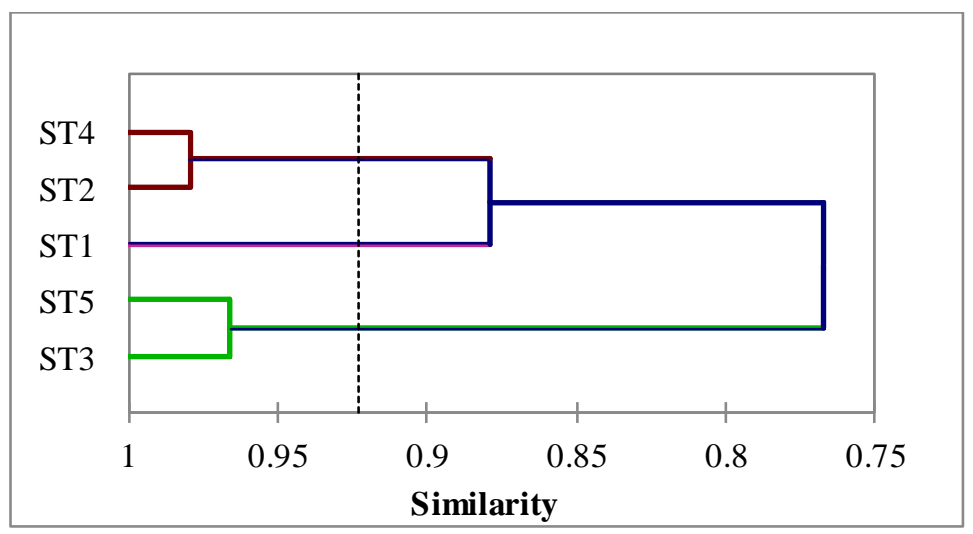

Figure 1. Hierarchical cluster analysis dendrogram of second-hand infant care samples 
The results of the hazard index by ingestion obtain for sample ST6 are presented in Table 3. The result shows that the majority of the toxic elements in the studied sample ST6 have a hazard index of less than 0.1 . Only three to xic elements have a HI higher than 0.1 with moderate hazard risk: arsenic As, cobalt Co and mercury $\mathrm{Hg}$, which means their toxicity should not be ignored. None of the toxic heavy metals has a hazard index higher than 1. The highest hazard index HI is detected was for arsenic with a value 0.5652 . After that come to $\mathrm{Hg}$ and $\mathrm{Co}$ with values of 0.2967 and 0.1211 respectively. The $\mathrm{HI}$ results show how unsafe second-hand infant care products are to the health of infants and reveals the need to take precautions when buying such products for infants because of their exposure to health concerns.

Table 3. Hazard indices of toxic elements in sample ST6 for infant exposure by ingestion.

\begin{tabular}{|c|c|c|c|c|c|c|c|c|c|c|c|c|c|c|}
\hline & Al & As & $\mathrm{Ba}$ & $\mathrm{Cd}$ & Co & $\mathrm{Cr}$ & $\mathrm{Cu}$ & $\mathrm{Hg}$ & $\mathrm{Mn}$ & $\mathrm{Ni}$ & $\mathrm{Pb}$ & Se & v & $\mathrm{Zn}$ \\
\hline Conc. (mg/kg) & 0.117 & 0.006 & 0.009 & 0.001 & 0.006 & 0.000 & 0.127 & 0.021 & 0.003 & 0.004 & 0.001 & 0.010 & 0.000 & 0.091 \\
\hline $\begin{array}{l}\text { Rmg ( } \mu \mathrm{g} / 10 \\
\mathrm{~g})\end{array}$ & 1.17 & 0.06 & 0.09 & 0.01 & 0.06 & 0 & 1.27 & 0.21 & 0.03 & 0.04 & 0.01 & 0.1 & 0 & 0.91 \\
\hline $\mathrm{EF}(\mathrm{min} / \mathrm{d})$ & 26 & 26 & 26 & 26 & 26 & 26 & 26 & 26 & 26 & 26 & 26 & 26 & 26 & 26 \\
\hline BW kg & 9.2 & 9.2 & 9.2 & 9.2 & 9.2 & 9.2 & 9.2 & 9.2 & 9.2 & 9.2 & 9.2 & 9.2 & 9.2 & 9.2 \\
\hline CDI ( $\mu \mathrm{g} / \mathrm{kg} . \mathrm{d})$ & 3.307 & 0.170 & 0.254 & 0.028 & 0.170 & 0.000 & 3.589 & 0.593 & 0.085 & 0.113 & 0.028 & 0.283 & 0.000 & 2.572 \\
\hline $\mathrm{RfD}(\mu \mathrm{g} / \mathrm{kg} \cdot \mathrm{d})$ & 750 & 0.3 & 600 & 0.5 & 1.4 & 5 & 83 & 2 & 160 & 10 & 3.6 & 5 & 3 & 500 \\
\hline $\mathrm{HI}$ & 0.0044 & 0.5652 & 0.0004 & 0.0565 & 0.1211 & 0.0000 & 0.0432 & 0.2967 & 0.0005 & 0.0113 & 0.0079 & 0.0565 & 0.0000 & 0.0051 \\
\hline
\end{tabular}

\section{Conclusion}

In this work, 14 to xic heavy metal concentrations have been investigated in 6 different samples of second hand infant care plastic products sold in markets in Kalar city, Kurdistan Region, Iraq. The chemical analysis of the samples showed considerable concentrations of most of the examined toxic elements according to the European Union EU safety limits (European Council 2009) for brittle, pliable, liquid and sticky toy materials. The statistical analysis using correlation matrix identified several strong positive correlations between toxic elements such as correlations between the elements $\mathrm{Al}, \mathrm{As}, \mathrm{Co}, \mathrm{Cr}, \mathrm{Hg}, \mathrm{Cu}$, and $\mathrm{Ni}$. While, $\mathrm{Pb}, \mathrm{Ba}$, and $\mathrm{Cd}$ have no correlations with other elements. Hierarchical cluster analysis HCA categorized the infant care sample to three distinct clusters in terms of to xicity. Similar conducts have been discovered between samples ST2 and ST4 and between samples ST3 and ST5.

Bioaccessibility and risk assessment from exposure of the sample ST6 by ingestion have revealed a moderate health risk for infant exposure to arsenic As, mercury $\mathrm{Hg}$, and cobalt Co respectively. It is clear that the health risk assessment performed in this study leads to paying more attention to health concerns related to the second-hand infant care products and also developing restricted programs to control dealing with such products in local markets.

\section{References}

Agency for Toxic Substances and Disease Registry (ATSDR) (2017) Minimal Risk Levels.

Becker M, Edwards S, Massey RI (2010) Toxic Chemicals in Toys and Children's Products: Limitations of Current Responses and Recommendations for Government and Industry Environ Sci Technol 44:79867991 doi:10.1021/es 1009407 
Ciesielski T, Weuve J, Bellinger DC, Schwartz J, Lanphear B, Wright RO (2012) Cadmium Exposure and Neurodevelopmental Outcomes in U.S. Children Environ Health Perspect 120:758-763 doi:10.1289/ehp.1104152

Cui X-Y, Li S-W, Zhang S-J, Fan Y-Y, Ma LQ (2015) Toxic metals in children's toys and jewelry: Coupling bioaccessibility with risk assessment Environ Pollut 200:77-84 doi:https://doi.org/10.1016/j.envpo1.2015.01.035

Decharat S (2017) Assessment of lead levels in some children's plastic toys Asia-Pacific Journal of Science and Technology 18:1026-1033

Delgado K, Quijada R, Palma R, Palza H (2011) Polypropylene with embedded copper metal or copper oxide nanoparticles as a novel plastic antimicrobial agent Lett Appl Microbiol 53:50-54 doi:doi:10.1111/j.1472-765X.2011.03069.x

Duruibe JO, Ogwuegbu M, Egwurugwu J (2007) Heavy metal pollution and human biotoxic effects International Journal of physical sciences 2:112-118

Earls AO, Axford IP, Braybrook JH (2003) Gas chromatography-mass spectrometry determination of the migration of phthalate plasticisers from polyvinyl chloride toys and childcare articles $\mathrm{J}$ Chromatogr A 983:237-246 doi:https://doi.org/10.1016/S0021-9673(02)01736-3

Erkens L, Hamers H, Hermans R, Claeys E, Bijnens M (2001) Lead chromates: A review of the state of the art in 2000 Surface Coatings International Part B: Coatings Transactions 84:169-176 doi:10.1007/bf02700395

European Council (2009) Directive 2009/48/EC of the European Parliament and of the Council of 18 June 2009 on the Safety of Toys. Brussels, Belgium

Felter SP, Daston GP, Euling SY, Piers ma AH, Tassinari MS (2015) Assessment of health risks resulting from early-life exposures: Are current chemical toxicity testing protocols and risk assessment methods adequate? Crit Rev Toxicol 45:219-244 doi:10.3109/10408444.2014.993919

Finch LE, Hillyer MM, Leopold MC (2015) Quantitative Analysis of Heavy Metals in Children's Toys and Jewelry: A Multi-Instrument, Multitechnique Exercise in Analytical Chemistry and Public Health J Chem Educ 92:849-854 doi:10.1021/ed500647w

Goldman LR (1998) Chemicals and children's environment: what we don't know about risks Environ Health Perspect 106:875-880

Greenway JA, Gerstenberger S (2010) An Evaluation of Lead Contamination in Plastic Toys Collected from Day Care Centers in the Las Vegas Valley, Nevada, USA Bull Environ Contam Toxicol 85:363 -366 doi:10.1007/s00128-010-0100-3

Grynkiewicz-By lina B (2011) Testing of toxic elements migration from the materials used as toy coatings Ecological Chemistry and Engineering S 18:223-231

Guney M, Nguyen A, Zagury GJ (2014) Estimating children's exposure to toxic elements in contaminated toys and children's jewelry via saliva mobilization Journal of Environmental Science and Health, Part A 49:1218-1227 doi:10.1080/10934529.2014.910028

Hervey TK, McHale JV (2004) Health law and the European Union. Cambridge University Press,

Hillyer MM, Finch LE, Cerel AS, Dattelbaum JD, Leopold MC (2014) Multi-technique quantitative analysis and socioeconomic considerations of lead, cadmium, and arsenic in children's toys and toy jewelry Chemosphere 108:205-213 doi:https://doi.org/10.1016/j.chemosphere.2014.01.041 
Issa HM, Alshatteri A (2018) Assessment of Heavy Metals Contamination in Drinking Water of Garmian Region, Iraq UHD Journal of Science and Technology:40-53\% V 42 doi:10.21928/uhdjst.v2n2y2018.pp40 53

Jaksland C, Ras mussen E, Rohde T (2000) A new technology for treatment of P VC waste Waste Manage (Oxford) 20:463-467 doi:https://doi.org/10.1016/S0956-053X(00)00012-X

Kakimov A, Kakimova Z, Yessimbekov Z, Bepeyeva A, Zharykbasova K, Zharykbasov Y (2013) Heavy metals distribution in soil, water, vegetation and meat in the regions of East-Kazakhstan Journal of Environmental Protection 4:1292

Kang S, Zhu J (2015) Total lead content and its bioaccessibility in base materials of low -cost plastic toys bought on the Beijing market J Mater Cycles Waste Manage 17:63-71 doi:10.1007/s 10163-013-0223-9

Kim HS, Kim YJ, Seo YR (2015) An Overview of Carcinogenic Heavy Metal: Molecular Toxicity Mechanism and Prevention Journal of Cancer Prevention 20:232-240 doi:10.15430/JCP.2015.20.4.232

Kopp B, Zalko D, Audebert M, Dertinger S (2018) Genotoxicity of 11 heavy metals detected as food contaminants in two human cell lines Environ Mol Mutag 59:202-210 doi:doi:10.1002/em.22157

Korfali SI, Sabra R, Jurdi M, Taleb RI (2013) Assessment of Toxic Metals and Phthalates in Children's Toys and Clays Arch Environ Contam Toxicol 65:368-381 doi:10.1007/s00244-013-9925-1

Landrigan PJ, Goldman LR (2011) Children's Vulnerability To Toxic Chemicals: A Challenge And Opportunity To Strengthen Health And Environmental Policy Health Aff 30:842-850 doi:10.1377/hlthaff.2011.0151

Landrigan PJ, Kimmel CA, Correa A, Eskenazi B (2004) Children's health and the environment: public health issues and challenges for risk assessment Environ Health Perspect 112:257-265

Lanphear BP et al. (2005) Low-Level Environmental Lead Exposure and Child ren's Intellectual Function: An International Pooled Analysis Environ Health Perspect 113:894-899 doi:10.1289/ehp.7688

Levin R et al. (2008) Lead Exposures in U.S. Children, 2008: Implications for Prevention Environ Health Perspect 116:1285-1293 doi:10.1289/ehp.11241

Luca F-A, Ciobanu C-I, Andrei A, Horodnic A (2018) Raising Awareness on Health Impact of the Chemicals Used in Consumer Products: Empirical Evidence from East-Central Europe Sustainability 10:209

Mahmood Q, Rashid A, Ahmad SS, Azim MR, Bilal M (2012) Current Status of Toxic Metals Addition to Environment and Its Consequences. In: Anjum NA, Ahmad I, Pereira ME, Duarte AC, Umar S, Khan NA (eds) The Plant Family Brassicaceae: Contribution Towards Phytoremediation. Springer Netherlands, Dordrecht, pp 35-69. doi:10.1007/978-94-007-3913-0_2

Marcovecchio JE, Botté SE, Freije RH (2007) Heavy metals, major metals, trace elements Handbook of water analysis 2:275-311

Miller GZ, Harris ZE (2015) Hazardous metals in vintage plastic toys measured by a handheld X-ray fluorescence spectrometer J Environ Health 77:8-13; quiz 113

Mizuno K, Hirukawa H, Kawasaki O, Noguchi H, Suzuki O (1999) Development of non-lead stabilized PVC compounds for insulated wires and cables Furukawa Review 18:111-118

Nada Abdulrahman FA-E, Faiza Kadhim E (2017) A Microbial Survey of Second Hand Clothe Samples Collected from Baghdad Market Journal of Al-Nahrain University - Science 20:127-136 
Nahar MS, Zhang J (2012) Assessment of potable water quality including organic, inorganic, and trace metal concentrations Environ Geochem Health 34:141-150 doi:10.1007/s 10653-011-9397-z

Nkono NA, Asubiojo OI (1997) Trace elements in bottled and soft drinks in Nigeria — a preliminary study Sci Total Environ 208:161-163 doi:https://doi.org/10.1016/S0048-9697(97)00289-1

Oke SA (2004) On the environmental pollution problem: A review Journal of Environmental Engineering and Landscape Management 12:108-113 doi:10.1080/16486897.2004.9636828

Rebelo A, Pinto E, Silva MV, Almeida AA (2015) Chemical safety of children's play paints: Focus on selected heavy metals Microchem J 118:203-210 doi:https://doi.org/10.1016/j.mic roc.2014.09.008

Rodríguez-Barranco M, Lacasaña M, Aguilar-Garduño C, Alguacil J, Gil F, González-Alzaga B, RojasGarcía A (2013) Association of arsenic, cadmium and manganese exposure with neurodevelopment and behavioural disorders in children: A systematic review and meta-analysis Sci Total Environ 454-455:562577 doi:https://doi.org/10.1016/j.scitotenv.2013.03.047

Scheuplein R, Charn ley G, Dours on M (2002) Differential Sensitivity of Children and Adults to Chemical Toxicity: I. Biological Basis Regul Toxicol Pharm 35:429-447 doi:https://doi.org/10.1006/rtph.2002.1558

Shen KK, Kochesfahani S, Jouffret F (2008) Zinc borates as mu ltifunctional poly mer additives Poly m Adv Technol 19:469-474 doi:doi:10.1002/pat.1119

Smith SA, Norris B (2003) Reducing the risk of choking hazards: Mouthing behaviour of children aged 1 month to 5 years Injury Control Safe Promot 10:145-154 doi:10.1076/icsp.10.3.145.14562

Stef DS, Gergen I (2012) Effect of mineral-enriched diet and medicinal herbs on Fe, Mn, Zn, and Cu uptake in chicken Chemistry Central Journal 6:19 doi:10.1186/1752-153x-6-19

Tulve NS et al. (2015) Characterization of silver nanoparticles in selected consumer products and its relevance for predicting children's potential exposures Int J Hyg Environ Health 218:345-357 doi:10.1016/j.ijheh.2015.02.002

Turner A (2018) Concentrations and Migratabilities of Hazardous Elements in Second-Hand Child ren's Plastic toys Environ Sci Technol 52:3110-3116 doi:10.1021/acs.est.7b04685

U.S. EPA (2005) Guidance for Monitoring and Assessing Childhood Exposures to Environmental Contaminants.

Van Engelen J et al. (2009) Chemicals in toys. A general methodology for assessment of chemical safety of toys with a focus on elements RIVM rapport 320003001

VanArsdale JL, Leiker RD, Kohn M, Merritt TA, Horowitz BZ (2004) Lead Poisoning From a Toy Necklace Pediatrics 114:1096-1099 doi:10.1542/peds.2004-0361

Weidenhamer JD, Miller J, Gu inn D, Pearson J (2011) Bioavailab ility of Cad miu m in Ine xpensive Jewelry Environ Health Perspect 119:1029-1033 doi:10.1289/ehp.1003011

Wigle DT, Arbuckle TE, Walker M, Wade MG, Liu S, Krewski D (2007) Environmental Hazards: Evidence for Effects on Child Health Journal of Toxicology and Environmental Health, Part B 10:3-39 doi:10.1080/10937400601034563 